\title{
Vegetation exploitation by barnacle geese Branta leucopsis during incubation on Svalbard
}

\author{
INGER GREVE ALSOS, ARVE ELVEBAKK and GEIR WING GABRIELSEN
}

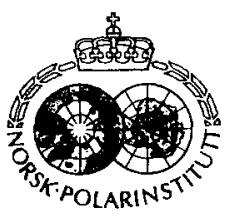

Alsos, I.G., Elvebakk, A. \& Gabrielsen, G.W. 1998: Vegetation exploitation by barnacle geese Branta
leucopsis during incubation on Svalbard. Polar Research $17(1), 1-14$.
The paper is a study of vegetation exploitation and the effect of food availability on the diet and behaviour
in barnacle geese breeding at Storholmen, Svalbard. Detailed vegetation mapping was used to estimate the
availability of food to individual pairs of geese. Diet composition was assessed through analysis of plant
fragments in droppings. The behaviour of geese in relation to snowmelt patterns was recorded. Most
vegetation types were exploited by the geese either for feeding or as nest substrate. Nest density was highest
and territories were smallest on early, snow-free ridges, although late breeding individuals also nested in
moss tundra vegetation. Most geese pairs exploited a mosaic of vegetation types in their territories, which
extended the feeding period when plants were nutritionally most profitable to the geese. Territory size
increased with decreasing density of the highest preferred food plants. Female geese preferred plants with
high nutrient quality, and the diet during incubation consisted of $41 \%$ flowers of forbs, $19 \%$ grasses, $6 \%$
leaves and buds of forbs, and $34 \%$ mosses. When the availability of grasses was <5\%, geese switched to a
diet dominated by the abundant, but nutrient-poor, mosses. The nutrient-poor diet resulted in more time off
the nest and less time being alert or searching for food during feeding bouts. Because nests are exposed to
predators when females feed or search for food, a low availability of nutrient-rich food within the territory
can affect hatching success.

1. G. Alsos and G. W. Gabrielsen, Norwegian Polar Institute, N-9005 Tromsø, Norway; A. Elvebakk, Institute of Biology and Geology, University of Troms $\phi, N-9037$ Troms $\phi$, Norway.

\section{Introduction}

When geese arrive at their arctic breeding grounds, snow still covers most of the vegetation (Madsen et al. 1989; Prop \& de Vries 1993; Spaans et al. 1993). Females rely on endogenous body reserves accumulated at southern spring staging areas for egg production and incubation (Ankney \& MacInnes 1978; Raveling 1979; Ebbinge \& Spaans 1995). However, smaller goose species, such as the barnacle goose, are also dependent on daily food intake during incubation (Ankney 1984; Afton \& Paulus 1992; Prop \& de Vries 1993).

Food availability during incubation is determined by when geese arrive at the nesting grounds and nest location (Inglis 1977; Prop et al. 1984; Madsen et al. 1989; Prop \& de Vries 1993; Spaans et al. 1993). Various vegetation types become available as snow cover melts, and the plant nutrient content varies within a season (Buchsbaum \& Valiela 1987; Sedinger \& Raveling 1986; Gauthier et al. 1995). For geese that feed only within their territories, plants growing within this area restrict dietary options. Because the quality and quantity of available food increase during the first weeks after snowmelt (Chapin et al. 1980; Prop \& de Vries 1993), the timing of nesting in relation to snowmelt patterns at the nest site might be important for nesting success.

Because ingestion efficiency in geese is poor (Mattocks 1971; Owen 1980; Sedinger et al. 1989), geese select food high in nutrients (Prop et al. 1980; Prop \& Deerenberg 1991; Gauthier 1993). During incubation, barnacle geese increase food retention time two- to fourfold compared to winter. Increased retention time enhances food digestion and allows diet extension by exploiting low quality food (Prop \& Vulink 1992). When nutrient rich food availability is low, it might be more profitable to feed on abundant but nutrient poor plants, if this requires less search time (Krebs \& Kacelnik 1993).

Due to the risk of egg predation (Harvey 1971; Inglis 1977; Prop et al. 1984) and the chilling of eggs (Eisenhauer \& Kirkpatrick 1977; Thompson \& Raveling 1987), there is strong pressure on geese to minimise the time spent off the nest searching for food. Studies have shown that the amount of time spent off the nest is directly 

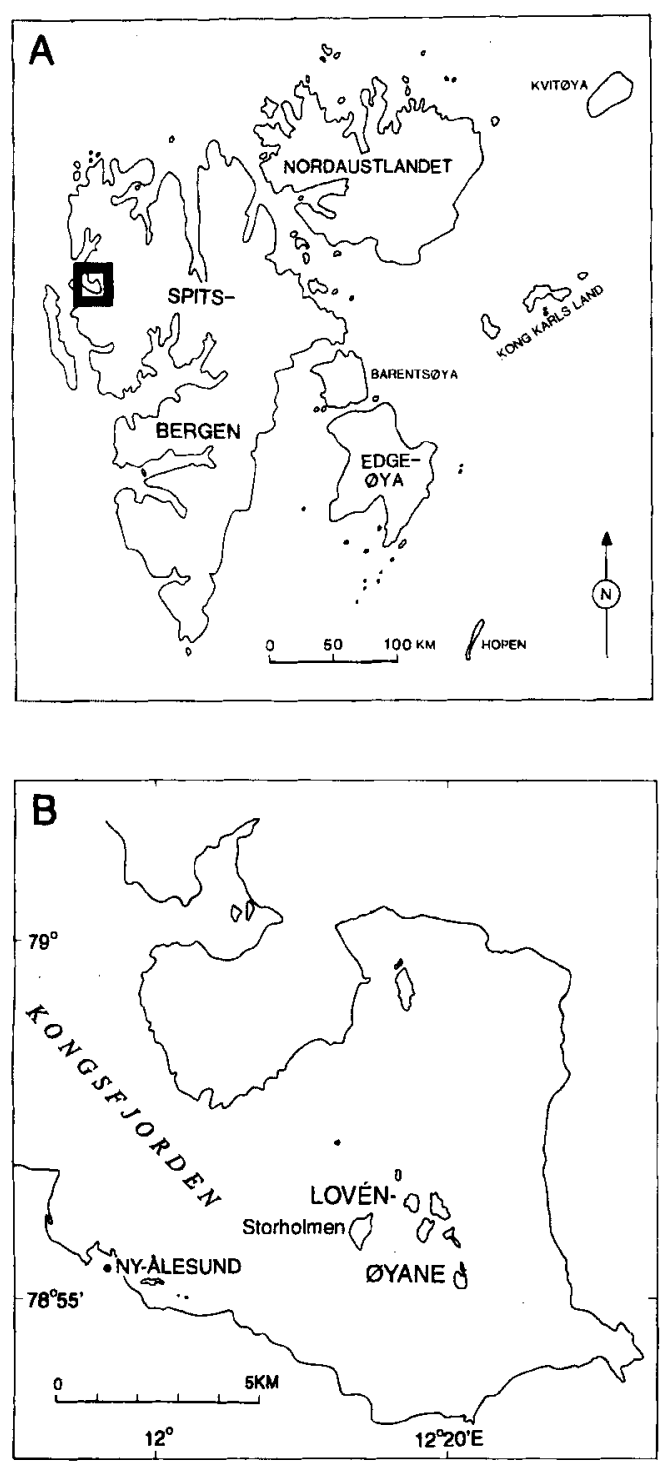

Fig. 1. A. The Svalbard archipelago showing the inner Kongsfjorden area and the location of the study site. B. The study area including the island Storholmen.

related to the physical condition of the female (review in Afton \& Paulus 1992). Prop et al. (1984) argued that time spent off the nest also relates to the net energy intake rate achieved while feeding. Although most barnacle geese nest in colonies, feeding in a common area away from the nest sites (Prop et al. 1980, 1984; Prop \& de
Vries 1993, see also review in Anderson \& Titman 1992), barnacle geese at Storholmen, Svalbard, fed exclusively in territories around nests. This provided a unique opportunity for studying the relationships between food availability, diet, and behaviour of the geese at an individual level.

The hypotheses of this study were threefold: (1) when feeding is restricted within a territory, the earliest snow-free areas will be preferred as nest substrate due to an advanced phenological stage of vegetation; (2) availability and nutrient content of plant species within the territory will influence diet selection and feeding behaviour; and (3) time spent off the nest during incubation could be inversely related to net energy intake rate, as suggested by Prop et al. (1984).

\section{Methods}

\section{Study area}

The study was conducted in 1993 at Storholmen in Kongsfjorden $\left(78^{\circ} 56^{\prime} \mathrm{N}, 12^{\circ} 13^{\prime} \mathrm{W}\right)$, Svalbard (Fig. 1). The research was concentrated in two areas where observation posts could be entered without disturbing the geese (Fig. 2). The highest point on the island was $33 \mathrm{~m}$ a.s.l. and variable topography gave rise to heterogeneous vegetation. Snowmelt streams and small ponds provided geese with fresh water throughout incubation (June-July). Vegetation at Storholmen benefits from the favourable climatic conditions in the inner part of the fjord and from deposit of faecal nitrogen by common eiders Somateria mollissima. Approximately 1700 pairs of common eiders were recorded nesting at Storholmen in 1993 (F. Mehlum pers. comm.). The grazing impact of herbivores other than barnacle geese was negligible on the island.

Storholmen is one of the earliest islands in Kongsfjorden to become free of sea-ice (Mehlum 1991). Arctic foxes Alopex lagopus usually do not occur on the island after the sea ice has melted. Arctic skua Stercorarius parasiticus, great skua $S$. skua and glaucous gull Larus hyperboreus are egg predators and were always present during the study.

The local population of barnacle geese in Kongsfjorden has increased from one breeding pair in 1982 (F. Mehlum, pers. comm.) to about 


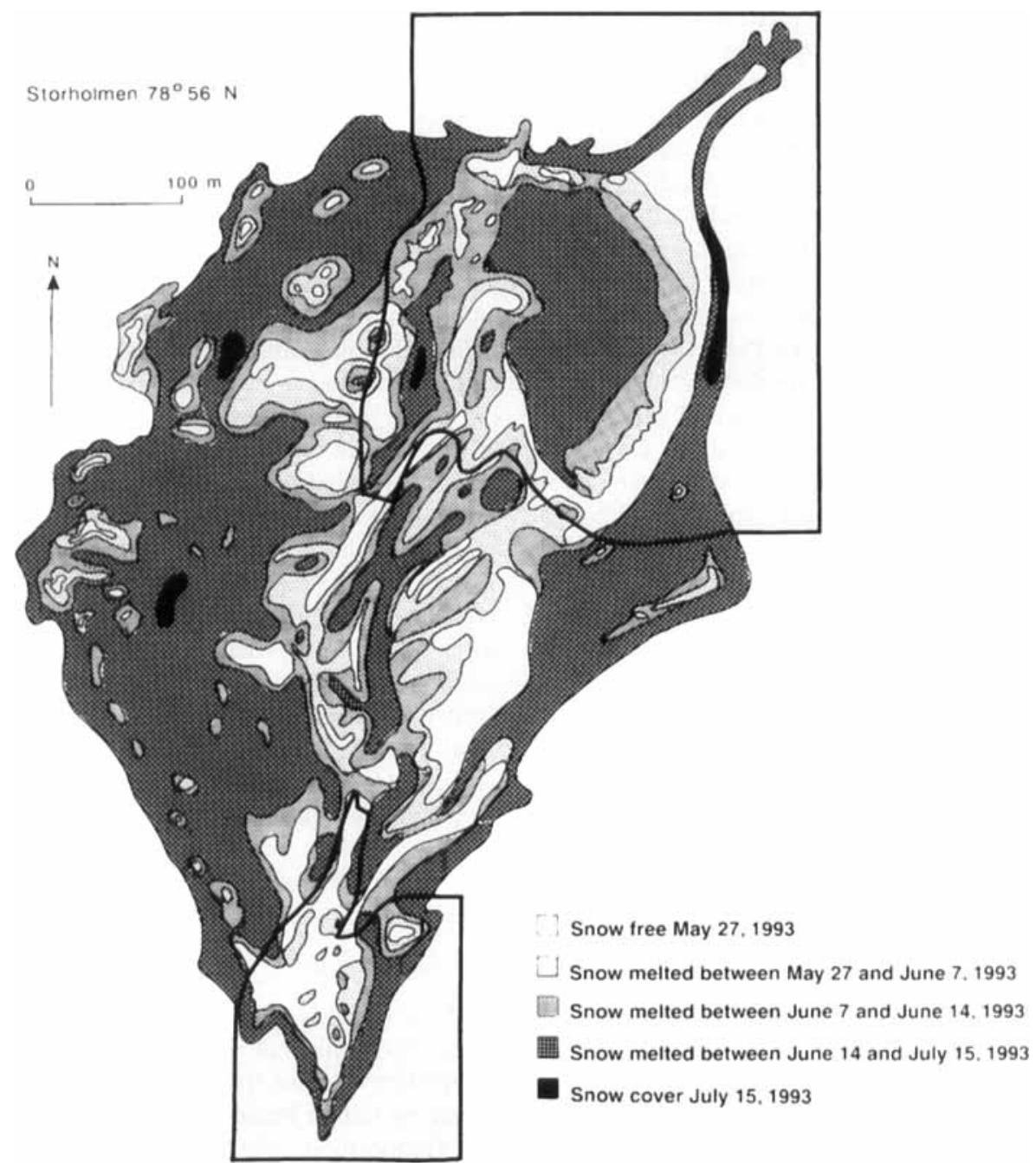

Fig. 2. Pattern of snowmelt at Storholmen, Svalbard, in 1993. Intensively studied areas are indicated within bold line.

300 breeding pairs in 1993. By 1993, almost $70 \%$ of the breeding population had been marked with individual-coded colour rings. Individuals could be identified by telescope up to $300 \mathrm{~m}$.

\section{Snow cover}

Colour slides of Storholmen were taken from aircraft (200-300 m a.s.1.) on May 27, June 7 and 14 , and July 15 in 1993. Snowmelt patterns were interpreted from these photographs and indicated on a map using an infrared aerial photograph (Norwegian Polar Institute) as cartographic basis.

\section{Vegetation mapping}

In late July, when most birds had finished incubation and left the island, we made a detailed vegetation map of the most intensively studied areas. Six major habitats were identified based on habitat ecology: exposed ridges, moss tundra, seepage areas, snow beds, eroded seashores, and strongly manured vegetation (mostly following 
Elvebakk 1994). Within each major habitat, a number of vegetation types were subjectively defined according to plant species composition and soil conditions. As barnacle geese prefer grasses and sedges as food (Prop et al. 1980, 1984), small, strongly manured vegetation patches (generally $<1 \mathrm{~m}^{2}$ ) with high density of grasses or sedges were included on the vegetation map. In total, 19 vegetation types were defined. An infrared aerial photograph (ca. 1:1300) from August 16, 1990 (Norwegian Polar Institute) was used as cartographic basis for the vegetation map.

We estimated plant cover (\%) of all species within every mapped vegetation stand. Cover for field layer (vascular plants) and bottom layer (cryptogams) was estimated separately although the height of the field layer seldom exceeded $10 \mathrm{~cm}$. Because cover was estimated on a vertical projection, values could exceed $100 \%$. Standing dead vegetation was generally low $(<10 \%)$ and was not included. Mosses and hepatics with less than $10 \%$ cover were recorded collectively as "Bryophytes spp.". Nomenclature follows Lid \& Lid (1994) for vascular plants and Frisvoll \& Elvebakk (1996) for bryophytes. The program ILWIS (Integrated Land and Water Information System) was used to present the vegetation map.

\section{Estimates of food availability within territories}

Nest sites were indicated on the vegetation map. The nesting range boundaries were defined by observing the female's feeding range (see below, "Behaviour"), and the outer boundaries were indicated as territory boundaries on the vegetation map. When two nests appeared to have overlapping territories, the common feeding range was defined and the estimated food availability was divided by two.

Total food availability was calculated as the area of each mapped vegetation stand within the territory multiplied by the \% plant cover of that stand. This gave an estimate of the area covered $\left(\mathrm{m}^{2}\right)$ of all plant species available to each pair of geese. Only edible plants were included in the estimate of food availability. Plant species comprising $1 \%$ or more of the dropping samples were characterised as edible. Available plants were grouped into four categories according to species and parts eaten by geese: grasses, forbs with edible flowers (=flowers), forbs with edible leaves or buds (=leaves), and mosses. According to the optimal foraging theory, intake of a food item depends on the availability of that food item and also on availability of alternative food (Krebs \& Kacelnik 1993). To compare feeding strategies for geese contending with different feeding situations, it was necessary to standardise availability estimates. The total areas of edible plants were set to $100 \%$, and the relative availability of the four plant categories was calculated as a proportion of the available food.

In performing analyses involving behaviour or diet, the relative availability per date was calculated by including only vegetation types free of snow cover for that date. Based on Prop \& de Vries (1993) and field observations, the following assumptions were made: moss species were available upon snowmelt, Salix spp. was available 5-12 days after snowmelt; and other forbs were available from $\geq 5$ days after snowmelt. Graminoids growing in dense patches on strongly manured, exposed sites were assumed to be available immediately after snowmelt. Graminoids growing intermixed in the moss carpet were assumed to be $50 \%$ available from day 10 after snowmelt and $100 \%$ from day 15 after snowmelt.

\section{Diet composition}

Fresh droppings were collected at rims of the nests. We collected most droppings after an observation bout so that diet could be related to the recent female behaviour. Furthermore, female diet composition could be related to the plant availability in the female's territory on that day. In total, 105 dropping samples, each consisting of 2-6 droppings, were collected from 40 females.

Droppings were analysed microscopically to assess the diet composition. Identification of plant species was based on epidermal cell structure following Owen (1975) but modified in that the samples were dried at $60^{\circ} \mathrm{C}$ for 48 hours, thereafter homogenised, and then temporally mounted in water. Fragments were examined every $2.5 \mathrm{~mm}$ along four transects until at least 100 fragments had been identified. Samples of plant species collected from the breeding grounds were used as reference material for the microscopical identification of fragments in the droppings. This method enabled us to estimate the proportion of plant species that were in the diet. Although the estimate is not equivalent to biomass ingested, 
we consider the estimate sufficiently accurate for the purpose of this study.

The nutrient content of some plant samples were analysed following the methods of Prop \& de Vries (1993). The nutrient values of plants collected on Storholmen were comparable to values of plants collected at the Diabasøya colony, and estimates of metabolisable energy content from the Diabas $\varnothing$ ya colony were therefore used (Prop \& de Vries 1993).

Relative selection of diet was calculated as \% of plant category $\mathrm{A}$ in diet minus relative $\%$ of plant category A within the territory, where A stands for flowers, leaves, grasses and mosses.

\section{Behaviour}

Eight diurnal observations bouts ( 24 hours) were conducted from June 18 to July 9, 1993. The females were noted at five-minute intervals to record the time spent incubating and off the nest. The total time the female was away from her nest during a 24-hour period was called "time off the nest". When the female left the nest, her feeding range was recorded by using natural markers. In total, 231 diurnal observations of time off the nest were recorded for 96 females, one to four observations per individual. On average, approximately $90 \%$ of the time off the nest was used for feeding. Accordingly, the accumulated grazing pressure exerted by a female was calculated as

(Time spent off the nest $\left(\mathrm{min} / \mathrm{day}^{-1}\right) * 0.9 * 24$ days of incubation) territory size $\left(\mathrm{m}^{2}\right)$

While the female was off the nest feeding, we recorded the proportion of time spent searching for food. Searching was defined as the head higher than the body, although this also may include alert behaviour.

Laying dates were collected by daily checking the nests during laying. If nests were recorded for the first time after clutch completion, laying dates were backdated assuming that the geese laid one egg per day, that no eggs were lost to predators, and that incubation lasted for 24 days (Dalhaug et al. 1996).

\section{Statistical analyses}

The program SPSS (Statistical Package for the Social Science) (Norusis 1986) was used for the statistical analyses. Data expressed as percentages were arcsin transformed which normalised dis- tributions in most cases. In performing analyses involving behaviour and availability data, mean values per female were used to avoid pseudoreplication. Only values for dates for which both variables had been measured were used when calculating means per female (e.g. when analysing effect of diet on time spent off the nest, only observations on time spent off the nest were included for dates when droppings from the observed female also had been collected). This was done to avoid seasonal changes in analyses. The untransformed data, with arcsin transformed linear regression lines, are presented below (Figs. 4, 6, 7 and 8) to facilitate interpretation. Means are presented \pm 1 standard error of the mean. Selection of nest habitat was calculated following Neu et al. (1974).

\section{Results}

\section{Settling in relation to snowmelt}

When the first geese arrived in the Kongsfjorden area in late May 1993, most of the vegetation was covered by snow (Fig. 2). An ice-bridge connected Storholmen to the mainland until June 3. After this date arctic foxes could no longer reach the island. Peak snowmelt occurred in the second week of June. Vegetation was closely related to snowmelt and hydrology patterns; wetness of vegetation increased with snow cover period (compare Fig. 2 with Fig. 3). Roughly, vegetation types A1 to A5 (the most exposed ridges) were snow free by May 27, vegetation types A6 to B1 (less exposed ridges and the driest moss tundra) were snow free by June 7, and vegetation types B2 to B5 (most moss tundra types) were snow free by June 14 . The remaining vegetation types $(\mathrm{B} 6, \mathrm{Cl}$ and D1) were snow free about June 20 (I.G. Alsos, pers. obs.). The close relationship between snowmelt and vegetation type made it possible to predict the phenological stage of the plants from the vegetation maps, and thus calculate the food availability within territories per date.

Geese began egg laying between June 3 and 16. The general settling pattern was with snowmelt at the nest, although some preferences for early melted, exposed ridge vegetation types was observed (Fig. 3). Because development of the vegetation depends on snowmelt, all the birds experienced a similar phenology of plants within their territories during incubation. Most pairs 

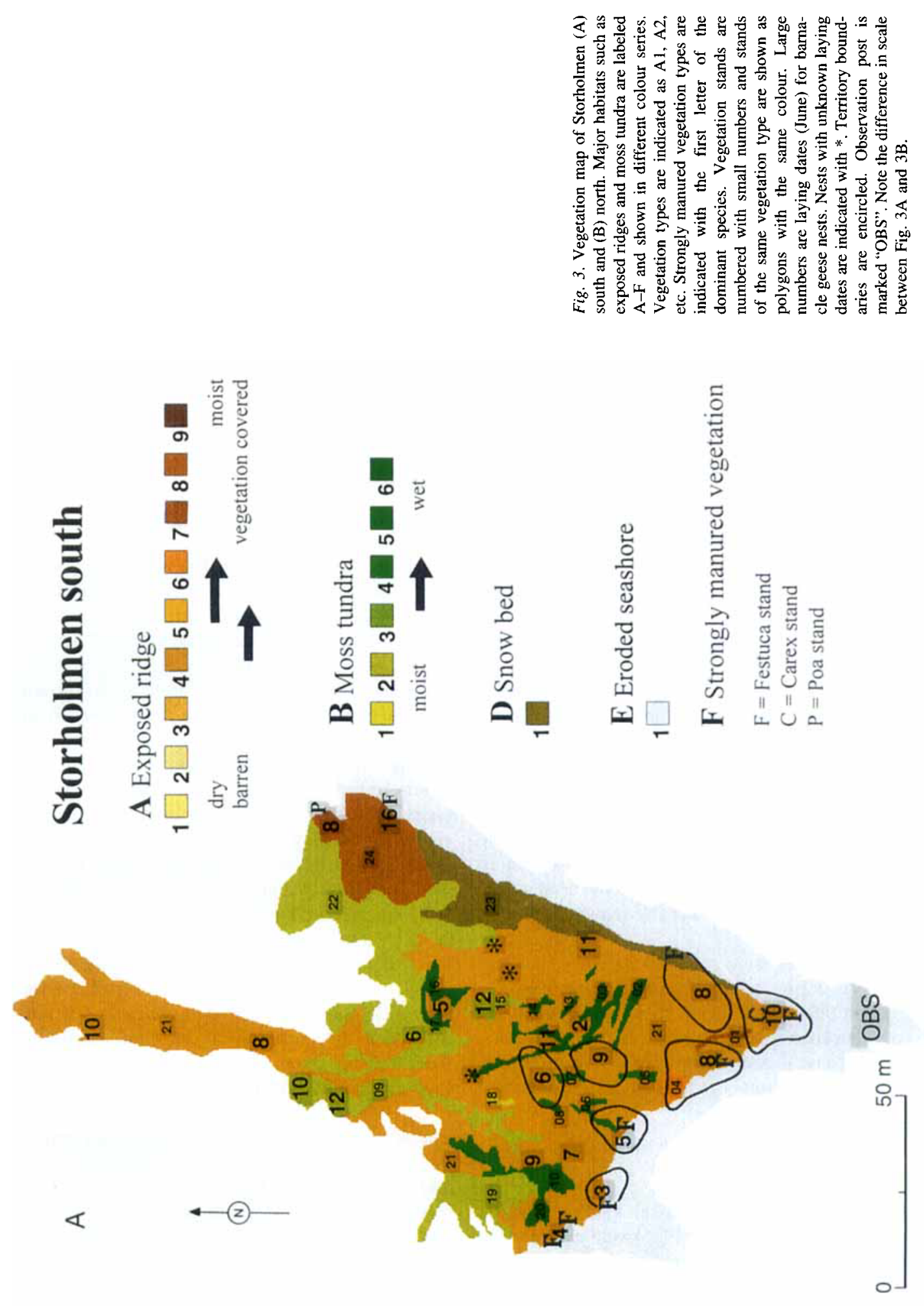
Vegetation exploitation by barnacle geese 7

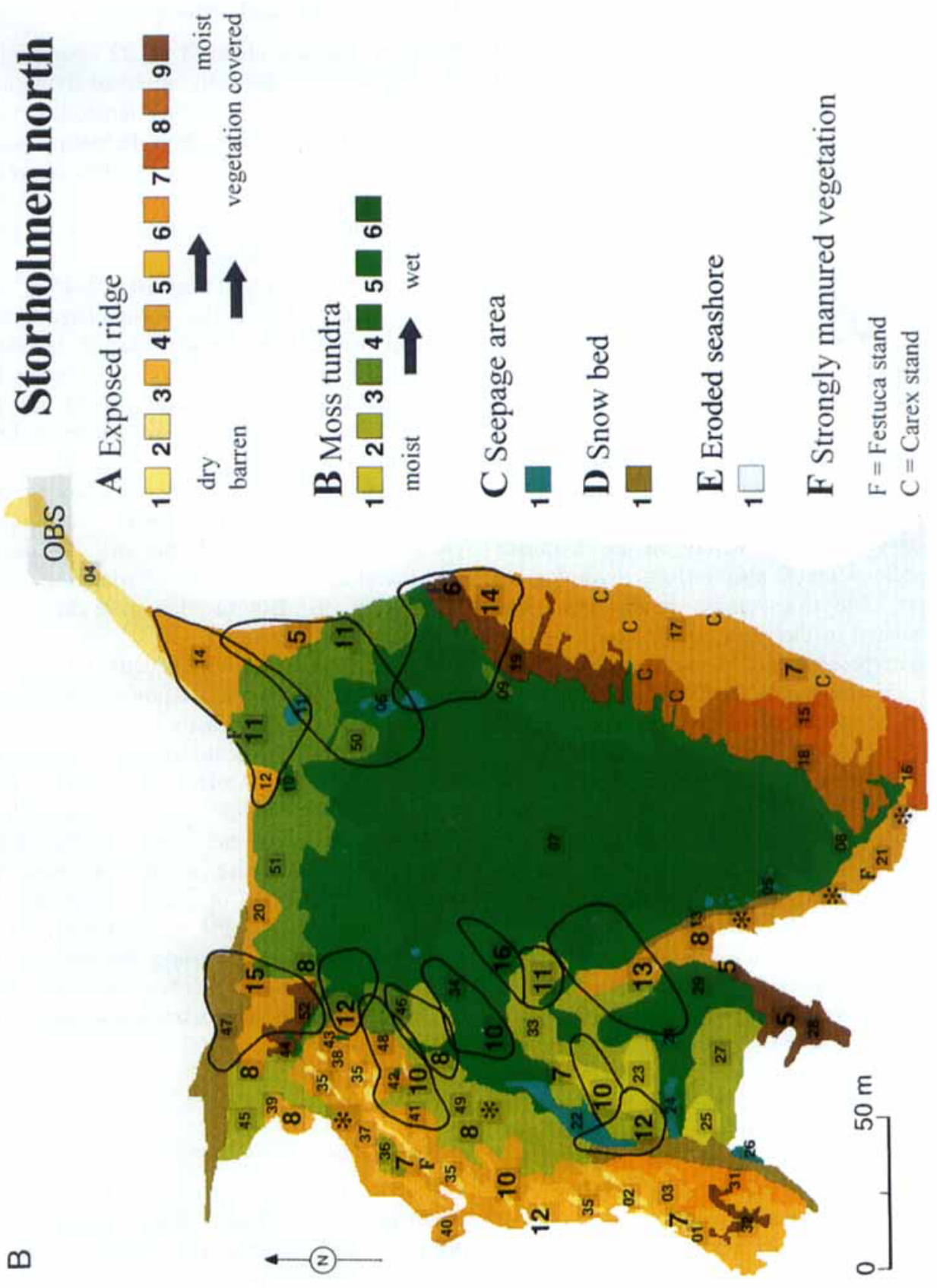


occupied territories consisting of a mosaic of exposed ridge and moss tundra vegetation types.

\section{Vegetation types and their use by geese}

Exposed ridge habitats were located on rocky outcrops and on beach ridges (Fig. 3). With nine vegetation types defined, this habitat type had the highest vegetation diversity, ranging from dry, barren and extremely exposed ridges to moist ridges with $100 \%$ plant cover. Soil under exposed ridge vegetation was of varying depths, but lacked peat. The floristic composition varied, but Salix polaris and Dryas octopetala were the dominant species (cover estimates for all mapped vegetation stands are presented in Alsos 1995). Most exposed ridge vegetation types were used as nest substrate. Forty-two nests were located in exposed ridge habitats, 15 more than expected if the nests had been distributed randomly among habitats $(\chi=14.8$, d.f. $=1, p<0.01)$. The nest density of this habitat was 11.2 and 9.1 nests per $\mathrm{km}^{2}$ (Storholmen south and Storholmen north respectively, Fig. 3).

Moss tundra was the dominating habitat type. It occurred on large plains, on gentle slopes and in depressions. Moss tundra was divided into six vegetation types based mainly on the dominant moss species, which also reflects hydrological conditions. The driest moss tundra type was closely related to the most moist, exposed ridge vegetation types, but was distinguished from these by peat development. Saxifraga species were important in all moss tundra vegetation types (Alsos 1995). Moss tundra was used by most geese for feeding and by late breeders as nest substrate (Fig. 3). The nest density was 5.1 and 3.1 nests per $\mathrm{km}^{2}$ (Storholmen south and Storholmen north, respectively). There were 16 nests in moss tundra habitat, 15 less than expected from random distribution $(\chi=14.8$, d.f. $=1, p<0.01)$.

Seepage areas surrounded small ponds of less than two $\mathrm{m}^{2}$. Most of the ponds were located in areas where there was a high level of run-off of water during snowmelt. Some geese were feeding on mosses in seepage areas. On sunny days, some geese were observed drinking from these ponds.

Snow bed habitats were found below ridges and on beach slopes. They were not available for nesting at the time of settling, but were used for feeding later in incubation (Fig. 3).

Strongly manured patches with a high density of graminoids were often found on gull perches on exposed sites and around old common eider nests. They were heavily grazed, which showed that they were important food sources for the geese. Breeders occupied all 12 graminoid patches dominated by grasses, 12 more than expected by random distribution $(\chi=9616$, d.f. $=1$, $\mathrm{p}<0.0001$ ) (Fig. 3).

\section{Food availability and territory size}

Territory size was obtained for 22 nests (Fig. 3). Females were occasionally observed flying a few hundred metres away from their territories, mainly to drink or bath on sunny days. In many cases the area defended by the male was slightly larger than the feeding range of the female, and the males were frequently observed feeding at the outer range of their territories.

Territory sizes ranged from 70 to $1445 \mathrm{~m}^{2}$, with a median of $390 \mathrm{~m}^{2}$. The accumulated grazing pressure exerted by females during incubation was $10 \pm 2.3 \mathrm{~min} \mathrm{~m}^{-2} 24$ days $^{-1}$. Extremely high accumulated grazing pressures $\left(27-43 \mathrm{~min} \mathrm{~m}^{-2}\right.$ $24 \mathrm{day}^{-1}$ ) were found in some small territories on Storholmen south (Fig. 3A), and agonistic behaviour was most frequently observed among males of these territories. The lowest accumulated grazing pressure $\left(1.5-2.5 \mathrm{~min} \mathrm{~m}^{-2} 24\right.$ days $\left.^{-1}\right)$ was found in territories with overlapping feeding ranges (Fig. 3B). Non-breeders were chased away if they entered a territory.

If the size of the territory is determined by food requirements, an inverse relationship between the territory size and the density of preferred food is expected. The size of the territory depended on the relative availability of edible plants $\left(\mathrm{F}_{2,19}=10.78, \mathrm{r}=0.73, \mathrm{p}<0.001\right.$, multiple regression with leaves and mosses in the model). There was a decrease in territory size with increasing availability of grasses suggesting that geese compensated for low availability of nutrient-rich food by increasing the territory size (Fig. 4). Territory size increased with increasing relative availability of mosses, a low quality food source (territory size $=1350$ mosses-503, $r=0.61$, $\mathrm{n}=22, \mathrm{p}<0.01$ )

\section{Diet}

The most important species in the diet were Saxifraga oppositifolia, Silene acaulis, Salix polaris, grasses and the mosses Sanionia uncinata, Tomentypnum nitens, Aulacomnium 
palustre, and Calliergon richardsonit. The diet composition throughout incubation for all females was $41 \pm 0.03 \%$ flowers of forbs, $19 \pm 0.02 \%$ grasses, $6 \pm 0.01 \%$ leaves and buds of forbs, and $34 \pm 0.04 \%$ mosses $(\mathrm{n}=40$, including 105 dropping samples from 40 females, mean values per female). Among the edible plant species, females generally selected food items with the highest estimated metabolisable energy content, although large variations among individuals were observed (Fig. 5).

Assuming that the geese preferred food in the sequence suggested by the metabolisable energy content of the plants (Fig. 5), multiple regression analysis using backward elimination strategy was performed between the proportion of food items in the diet and relative availability of more highly preferred food items in the territory. The proportion of mosses in the diet depended on the availability of grasses and flowers in the territory $\left(F_{2.19}=3.77, \%\right.$ mosses in diet $=0.456-0.583$ grasses +0.297 flowers, $r=0.53, p<0.05$ ). The proportion of mosses in the diet tended to decrease with increasing relative availability of grasses in the territory, suggesting that intake of grasses was limited by availability (Fig. 6). The proportion of leaves in the diet increased with availability of grasses in the territory $\left(\mathrm{F}_{1,20}=4.74, \mathrm{r}=0.44, \mathrm{p}<0.05\right)$ whereas the proportion of flowers in the diet was independent of relative availability of the more highly preferred grasses in the territory $(\mathrm{p}>0.1)$.

\section{Behaviour}

The proportion of time spent searching while feeding increased with the proportion of flowers in the diet and decreased with the proportion of mosses in the diet (Fig. 7). A decrease in the proportion of search time was found with increasing time spent off the nest (Fig. 8).

The mean time spent off the nest ranged from 25 to 397 minutes per day for individual females. The average of all females was $145 \pm 6.25$ minutes per day (including 231 diurnal observations on 96 females, mean values per female). Time spent off the nest decreased with the proportion of flowers in the diet and tended to increase with the proportion of mosses in the diet (Fig. 9).

Individuals with graminoid patches in their territory spent less time off the nest than those without (with graminoid patches: $102 \pm 15$ $(\mathrm{n}=10)$, without graminoid patches: $139 \pm 11$ $(n=24)$ minutes per day, but the difference was not statistically significant $(t=1.81$, d.f. $=34$, $p=0.08$ ).

\section{Discussion}

\section{Selection of nest sites}

Patterns of snowmelt strongly influenced the selection of nest sites at Storholmen. The highest nest densities were found in early melted areas, as also observed in other goose species (e.g. Eisenhauer \& Kirkpatrick 1977; Madsen et al. 1989; Bruggink et al. 1994). The highest grazing pressures and smallest territory sizes were also found here. However, because exposed ridge vegetation types had similar availability of edible plants as most moss tundra types (Alsos 1995), we interpret these findings as a selection for early melting nest sites rather than a selection for exposed ridge vegetation types. Later nesting individuals used the later melted moss tundra as nest substrate. Thus, all individuals experienced similar phenological development of the vegetation within their territories during incubation. The only vegetation types the geese showed a preference for were strongly manured grass patches. Having grass aggregated in patches is probably important because the bite rate obtained by grazing on tussock grasses is about twice the bite rate of grazing on single-stemmed grasses (Trudell \& White 1981). Also, the grass patches at the bird perches are situated on ridges with an early phenological development, making them attractive as food sources. The wettest moss tundra vegetation types apparently became snow free too late to be used as nest substrate.

Many territories had an asymmetric shape. We interpret this as a selection for a vegetation gradient from early melted exposed ridge vegetation to late melted moss tundra. This enabled the territorial geese at Storholmen to feed along the retreating snow and resulted in extending the period of plants in the most nutrient rich stage. Feeding along retreating snow has been observed for several goose species (Prop et al. 1980, 1984; Fox et al. 1991; Gauthier 1993; Prop \& de Vries 1993) and mammals (Langvatn \& Albon 1986). Feeding along retreating snow optimises nutrient 


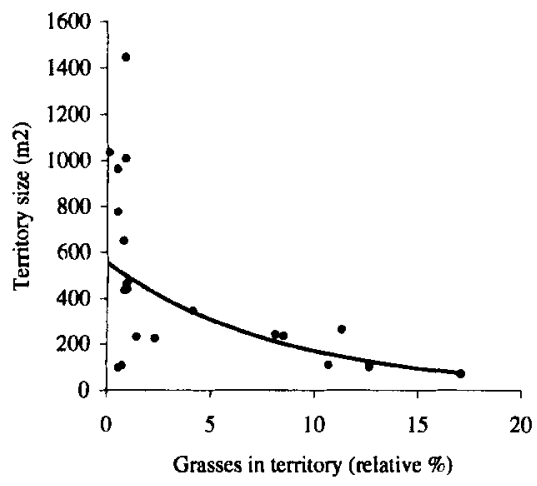

Fig. 4. The relationship between territory size and relative availability of grasses in the territory of barnacle geese on Storholmen, Svalbard. $y=825-2001 \arcsin (\operatorname{sgrt}(x)), r=-0.61$, $n=22, p<0.01$. Two points are hidden due to identical values.

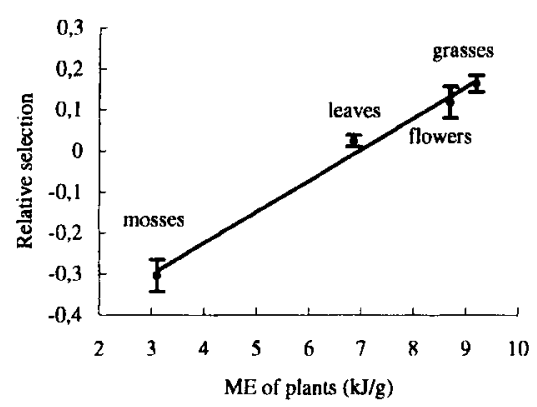

Fig. 5. Relative selection of diet by female barnacle geese in relation to metabolisable energy (ME) content of the plants (ME after Prop \& de Vries 1993). Each point within food categories corresponds to the mean diet throughout incubation for all females, and each female is represented in all four food categories. The regression is: $\mathrm{y}=0.074 \mathrm{x}-0.515, \mathrm{r}=0.64$, $\mathrm{n}=88, \mathrm{p}<0.0001$.

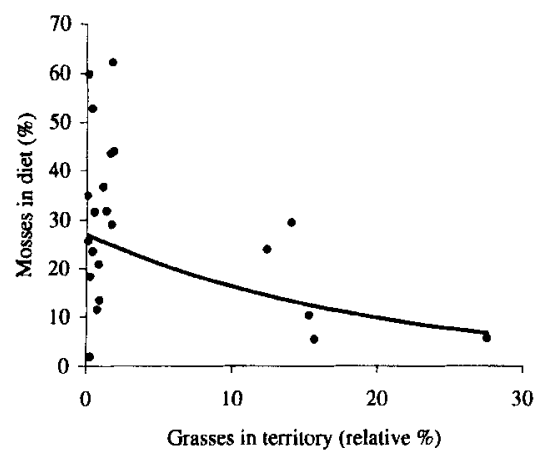

Fig. 6. Percent mosses in the diet of female barnacle geese in relation to relative availability of grasses in the territory. The regression is: $y=\sin \left(0.626-0.560^{*} \arcsin (\operatorname{sqrt}(x))\right)^{2}, r=-0.41$, $\mathrm{n}=22$. $\mathrm{p}<0.06$, including 71 measurements on 22 individuals, mean values per female.
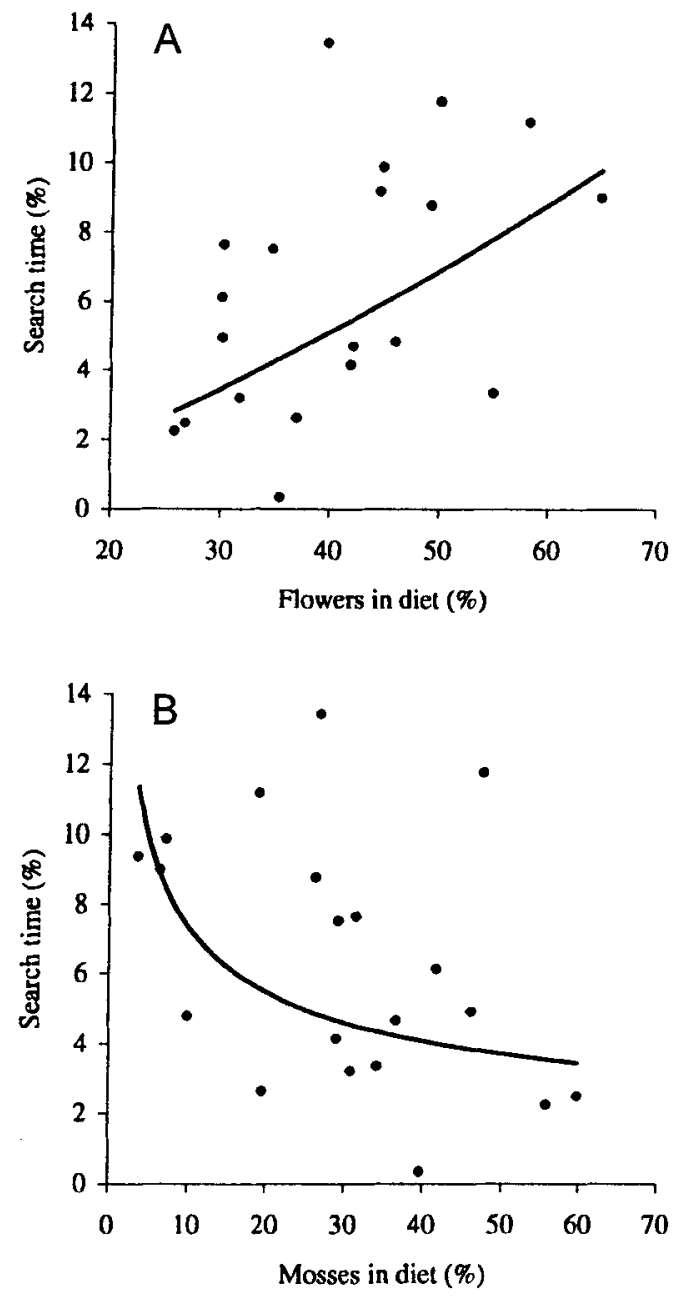

Fig. 7. Time spent searching for food by barnacle geese in relation to diet composition. A. Flowers $y=\sin$ $(0.0006+0.351 * \arcsin (\operatorname{sqrt}(x)))^{2}, \quad r=0.48, \quad \mathrm{n}=20, \mathrm{p}<0.05$. B. Mosses $y=\sin \left(0.348-0.186^{*} \arcsin (\operatorname{sqrt}(x))\right)^{2}, r=-0.44$, $\mathrm{n}=20, \mathrm{p}<0.05$. Including 38 observations on 20 females, mean values per female.

intake at a time when the green biomass is low. Mosses have highest nutrient value when the ground is still frozen and the geese can select only the fresh nutrient rich parts. The nutrient value to geese of Salix polaris is highest before the buds break (Prop \& de Vries 1993; Alsos unpubl.).

An inverse correlation was found between territory size and grass cover, suggesting that food availability determined the territory size. Owen \& Wells (1979) argued that territorial behaviour in barnacle geese served to protect the nest from being taken over by intruding birds or 


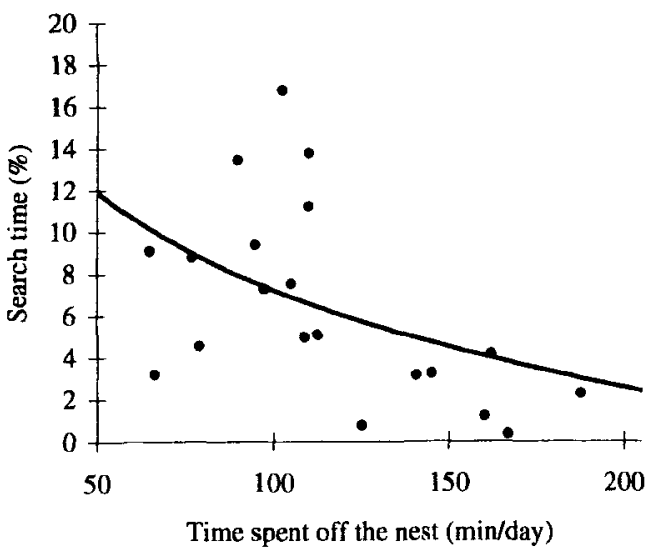

Fig. 8. Time spent searching for food or alert in relation to the time spent off the nest for barnacle geese breeding at Storholmen, Svalbard. $y=\sin \left(040-0.001^{*} x\right)^{2}, \quad r=-0.56$, $p<0.01$. Including 32 observations on 21 females, mean values per female.

egg dumping by parasitic females. However, they recognised that food availability within the territory would benefit both parents. These authors also suggested that food supply could determine the territory size, as we observed.

The distance from Storholmen to alternative feeding sites on the mainland is more than $3 \mathrm{~km}$, and non-breeders grazed the nearby islands. Flying demands more energy than walking (4-6 and 1.5 times basal metabolic rate respectively, $G$.
W. Gabrielsen unpubl. data) and lengthens the recess time (Spaans et al. 1993). We believe that the long distance to alternative feeding sites combined with the rich vegetation at Storholmen is the reason that geese at Storholmen were feeding in exclusive territories whereas barnacle geese breeding on other sites are nesting in colonies (Prop et al. 1980, 1984; Anderson \& Titman 1992; Prop \& de Vries 1993; Alsos pers. obs.).

\section{Selection of diet}

Female barnacle geese preferred plants according to their estimated metabolisable energy content. Selection for flowers and grasses indicated that nutrient demands for breeding were not met by a high consumption of low quality food. Prop et al. (1984) concluded that the geese were striving to assemble a diet composed of a mixture of different plants. Diet composition observed in our study was similar to the diet composition observed at the Diabasøya colony (Prop et al. 1984). There may be some demands for minerals or trace elements that make the geese choose a varied diet (Krapu \& Reinecke 1992). However, arctic vegetation probably provides sufficient minerals and trace elements (Chapin et al. 1975; Staaland et al. 1983). More likely, a low and patchy availability of preferred food items caused the mixed diet.

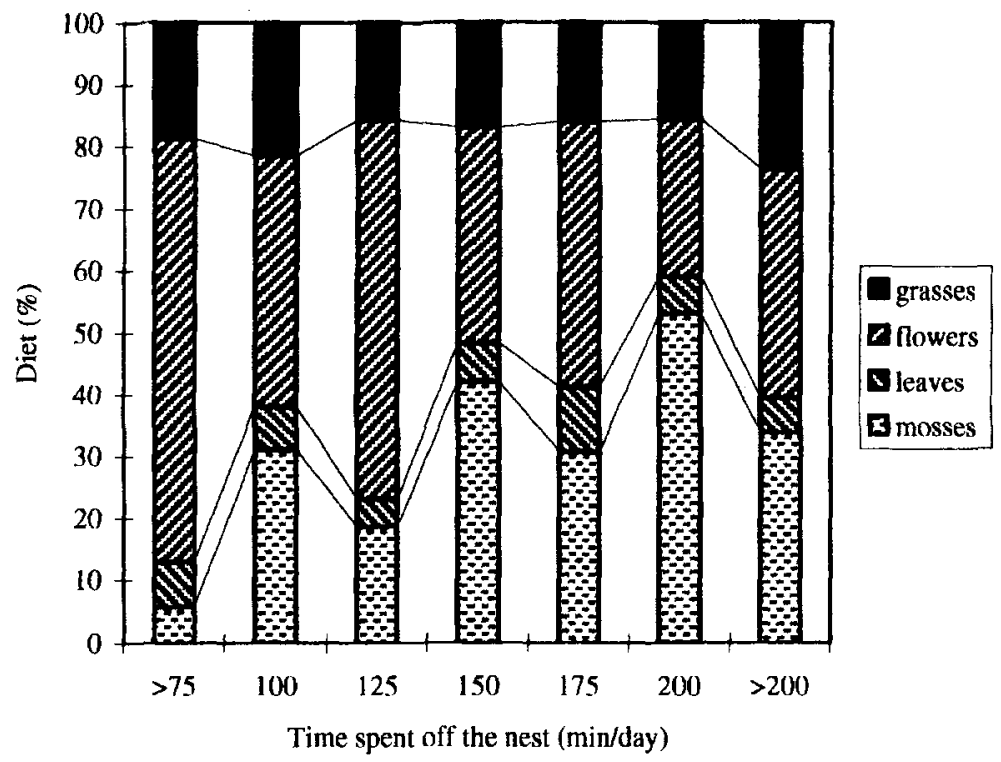

Fig. 9. Time spent off the nest in relation to diet composition. Grasses $\mathrm{p}=0.76$; flowers $y=189.6-68.5 x, r=-0.33$, $\mathrm{p}<0.05$; leaves $\mathrm{p}=0.83$; mosses $\mathrm{p}=0.09$; including 69 measurements on 37 females, mean values per female. The dependent is on the $\mathrm{x}$-axis to facilitate interpretations. Numbers above each bar are the sample size. 
A high proportion of mosses in the diet of most females indicated that the intake of highly preferred food items was limited. The intake of flower parts did not seem to be constrained by availability. This may be due to extremely favourable weather conditions. In the year of this study (1993), the ambient temperatures at the $\mathrm{Ny}$ Allesund meteorological station nearby were 0.8 , 0.9 and $1.1^{\circ} \mathrm{C}$ above mean for the last 30 years for May, June and July respectively (Aune 1993; Vervarslinga for Nord-Norge 1995 pers. comm.). This has probably caused a higher frequency of flowering in 1993 than in an average summer. The proportion of flower parts in the diet was twice as high in 1993 as in 1992, supporting this assumption $(41 \pm 0.03(n=105)$ and $20 \pm 0.02(n=68)$ respectively, Alsos unpubl.).

When the relative availability of grasses was $<5 \%$, it seemed to be more profitable for the geese to feed on mosses than spend time searching for grasses. The density of grasses, rather than the total amount of grass, probably limited intake because some individuals with a high proportion of mosses in their diet could have expanded their territories without interfering with other geese. In years with less favourable weather conditions and subsequently lower growth rates of plants, the geese might not be able to obtain sufficient nutrients in areas where the density of preferred food item is low. Consequently, in an average year, some parts of Storholmen used for breeding in 1993 can become inadequate as nesting habitats. Thus, when evaluating habitat quality, it is important to focus on preferred food items (Sedinger \& Raveling 1984; Hobbs \& Hanley 1990; Mansau \& Gauthier 1993).

\section{The influence of feeding conditions on time spent off the nest}

Individuals with a graminoid patch in their territory tended to spend less time off the nest. Several studies show that time spent feeding is related to feeding conditions, both in barnacle geese (Prop et al. 1984; Black et al. 1991; Prop \& de Vries 1993) and other goose species (Madsen 1985; Sedinger \& Raveling 1988; Giroux \& Bedard 1990; Spaans et al. 1993). The inverse relation between diet quality and time spent off the nest confirmed that individuals foraging for a long time tried to compensate for a low intake rate.
Geese breeding at Storholmen spent on average 145 minutes feeding per day, whereas barnacle geese breeding in the Diabasøya colony spent only 49 minutes off their nests in years with early snowmelt (Prop et al. 1984). Because the grazing pressure exerted by females at Storholmen was about ten times as high as observed for males and females in the Diabasøya colony (Prop et al. 1984), females at Storholmen probably tried to compensate for a low intake rate. The hatching success at Storholmen was similar to the hatching success observed at the Diabasøya colony in seasons of early snowmelt (Prop et al. 1984; Dalhaug et al. 1996; Tombre \& Erikstad 1996). The female at Storholmen could feed more because both she and the gander could observe the nest while she was feeding.

In conclusion, pattern of snowmelt was the most important factor in determining selection of nest sites on Storholmen. When the availability of grasses was low, the geese ate more mosses, and the nutrient poor diet obtained was related to longer time spent off the nest. Although no causal relationship can be inferred, this suggests that the density of high quality food at the nest sites can affect the hatching success of barnacle geese on Svalbard.

Acknowledgements. - This study is a part of the project "Reproduction ecology and energy allocation of Barnacle geese on Svalbard" (project no. 101618/720), financed by the Norwegian Research Council. Financial support was also provided by the University of Troms $\emptyset$, the Norwegian Polar Institute (scholarship no. 41/93) and the Foundation for Nature Research and Cultural Heritage Research, Department for Arctic Ecology. The Norwegian Research Council also provided a one year scholarship for I. G. Alsos to study at the University of Groningen, The Netherlands. We thank I. M. Tombre, L. Dalhaug, K. E. Erikstad and H. Skarsfjord for assistance during fieldwork. The staff at the Norwegian Polar Institute, Ny-Ålesund, provided logistics support. Furthermore, we would like to thank R. Drent and $M$. Loonen for inviting I. G. Alsos to study at the Zoological Laboratory, University of Groningen, The Netherlands. M. Loonen and J. Prop gave extensive help with analysing the data. I. M. Tombre, A. Kirchhefer, T. Alm and R. Barrett gave useful comments on early drafts of the manuscript. C. Wegener and $\mathbf{J}$. Oksanen kindly reviewed a recent draft of the manuscript. A. Derocher helped edit the language.

\section{References}

Afton, A. D. \& Paulus, S. L. 1992: Incubation and brood care. Pp. 62-108 in Batt, B. D. J., Afton, A. D., Anderson, M. G., Ankney, C. D., Johnson, D. H., Kadlec, J. A. \& Krapu, G. L. (eds.): Ecology and management of breeding waterfowl. University of Minnesota Press, Minneapolis and London. 
Alsos, I. G. 1995: The relationship between nest site, diet and behavior in Bamacle geese Branta leucopsis in Kongsfjorden, Svalbard. Cand. Scient. Thesis, University of Troms $\emptyset$, $62 \mathrm{pp}$.

Anderson, M. G. \& Titman, R. D. 1992: Spacing patterns. Pp. 251-289 in Batt, B. D. J., Afton, A. D., Anderson, M. G., Ankney, C. D., Johnson, D. H., Kadlec, J. A. \& Krapu, G. L. (eds.): Ecology and management of breeding waterfowl. University of Minnesota Press, Minneapolis and London.

Ankney, C. D. 1984: Nutrient reserve dynamics of breeding and molting Brant. Auk 101, 361-370.

Ankney, C. D. \& MacInnes, C. D. 1978: Nutrient reserves and reproductive performance of female Lesser Snow Geese. Auk 95, 459-471.

Aune, B. 1993: Air temperature normals, normal period 19611990. DNMI-Rapport 02/93 KLIMA. Det Norske Meterologiske Institutt, Oslo.

Black, J. M., Deerenberg, C. \& Owen, M. 1991: Foraging behaviour and site selection of Barnacle geese Branta leucopsis in traditional and newly colonised spring staging habitat. Ardea 79, 349-358.

Bruggink, J. G., Tacha, T. C. \& Davies, J. C. 1994: Nesting and brood-rearing ecology of Mississippi Valley population of Canada Geese. Wildl. Monogr. I26, 1-39.

Buchsbaum, R. \& Valiela, I. 1987: Variability in the chemistry of estaurine plants and its effects on feeding by Canada Geese. Oecologia 73, 146-153.

Chapin, F. S. III, Johnson, D. A. \& McKendrick, J. D. 1980: Seasonal nutrient allocation patterns in various tundra life forms in northem Alaska: implications for herbivory. J. Ecol. $68,189-209$.

Chapin, F. S. III, van Cleve, K. \& Tiezen, L. L. 1975: Seasonal nutrient dynamics of tundra vegetation at Barrow, Alaska. Arct. Alp. Res. 7, 209-226.

Dalhaug, L., Tombre. I. M. \& Erikstad, K. E. 1996: Seasonal decline in clutch size of the Barnacle Goose in Svalbard. Condor 98, 42-47.

Ebbinge, B. S. \& Spaans, B. 1995: The importance of body reserves accumulated in spring staging areas in the temperate zone for breeding in Dark-bellied Brent Geese Branta $b$. bernicla in the High Arctic. J. Avian Biol. 26, 105-113.

Eisenhauer, D. I. \& Kirkpatrick, C. M. 1977: Ecology of the Emperor Goose in Alaska. Wildl. Monogr. $57.62 \mathrm{pp}$.

Elvebakk, A. 1994: A survey of plant associations and alliances from Svalbard. J. Vegetation Science 5, 791-802.

Fox, A. D., Gitay, H., Boyd, H. \& Tomlinson, C. 1991: Snowpatch foraging by Pink-footed Geese Anser brachyrhynchus in south Iceland. Holarct. Ecol. 14, 81-84.

Frisvoll, A. A. \& Elvebakk, A. 1996: Part VIII. Bryophytes. In Elvebakk, A. \& Prestrud, P. (eds.): A Catalogue of Svalbards Plants, Fungi, Algae and Cyanobacteria. Norsk Polarinst. Skr. 198

Gauthier, G. 1993: Feeding ecology of nesting Greater Snow Geese. J. Wildl. Manage. 57, 216-223.

Gauther, G., Hughes, R. J., Reed, A. Beaulieu, J. \& Rochefort, L. 1995: Effect of grazing by Greater Snow Geese on the production of graminoids at an arctic site (Bylot Island, NWT, Canada). J. Ecol. 83, 653-664.

Giroux, J. F. \& Bédard, J. 1990: Activity budgets of Greater Snow Geese in fall. Can. J. Zool. 68, 2700-2702.

Harvey, J. M. 1971: Factors affecting Blue Goose nesting success. Can. J. Zool. 49, 223-234.
Hobbs, N. T. \& Hanley, T. A. 1990: Habitat evaluation: do use/ availability data reflect carrying capacity? $\mathrm{J}$. Wildl. Manage. 54, 515-522.

Inglis, I. R. 1977: The breeding behaviour of the Pink-footed Goose: Behaviour correlates of nesting success. Anim. Behav. 25, 747--764.

Krapu, G. L. \& Reinecke, K. J. 1992: Foraging ecology and nutrition. Pp. 1-29 in Batt, B. D. J., Afton, A. D., Anderson, M. G., Ankney, C. D., Johnson, D. H., Kadlec, J. A. \& Krapu, G. L. (eds.): Ecology and management of breeding waterfowl. University of Minnesota Press, Minneapolis and London.

Krebs, J. R. \& Kacelnik, A. 1993: Decision-making. Pp. 105 136 in Krebs, J. R. \& Davies, N. B. (eds.): Behavioural ecology. An evolutionary approach. Third edition. Blackwell Scientific Publications, Oxford.

Langvatn, R. \& Albon, S. D. 1986: Geographic clines in body weight of Norwegian red deer: a novel explanation of Bergmann's rule? Holarct. Ecol. 9, 285-293.

Lid, J. \& Lid, D. T. 1994: Norsk flora. Sixth edition. Det Norske Samiaget, Oslo. 1014 pp.

Madsen, J. 1985: Relation between change in spring habitat selection and daily energetics of Pink-footed Geese Anser brachyrhynchus. Ornis Scand. 16, 222-228.

Madsen, J., Bregnballe, T. \& Mehlum, F. 1989: Study of the breeding biology and behaviour of the Svalbard population of Light-bellied Brent Goose Branta bernicla hrota. Polar Res. 7, 1-21.

Mansau, M. \& Gauthier, G. 1993: Interactions between Greater Snow Geese and their rearing habitat. Ecology 74, 20452055.

Mattocks, J. G. 1971: Goose feeding and cellulose digestion. Wildfowl 22, 107-113.

Mehlum, F. 1991: Breeding population size of the Common Eider Somateria mollissima in Kongsfjorden, Svalbard 1981-1987. Nor. Polarinst. Skr. 195, 21-29.

Neu, C. W., Byers, C. R. \& Peek, J. M. 1974: A technique for analysis of utilization-availability data. $J$. Wildl. Manage. 38, $541-545$.

Norusis, M. J. 1986: SPSS/PC+ Base manual. SPSS Inc., Chicago.

Owen, M. 1975: An assessment of fecal analysis technique in waterfowl feeding studies. J. Wildl. Manage. 39, 271-279.

Owen, M. 1980: Wild geese of the world. BT Batsford Lid, London.

Owen, M. \& Wells, R. L. 1979: Territorial behaviour in breeding geese - a re-examination of Ryder's hypothesis. Wildfowl 30, 20-26.

Prop, J. \& de Vries, J. 1993: Impact of snow and food conditions on the reproductive performance of Barnacle geese Branta leucopsis. Ornis Scan. 24, 110-121.

Prop, J. \& Deerenberg, C. 1991: Spring staging in Brent Geese Branta bernicla: feeding constraints and the impact of diet on the accumulation of body reserves. Oecologia 87, 19-28.

Prop, J., van Eerden, M. R., Daan, S., Drent, R. H., Tindbergen, J. M. \& St. Joseph, A. M. 1980: Ecology of the Barnacle Goose Branta leucopsis during the breeding season: preliminary results from expeditions to Spitzbergen in 1977 and 1978. Pp. 50-112 in Proceedings of the NorwegianNetherlands Symposium on Svalbard. Arctic Center, Groningen. 


\section{I. G. Alsos et al.}

Prop, J., van Erden. M. R. \& Drent, R. H. 1984: Reproductive success of the Barnacle Goose Branta leucopsis in relation to food exploitation on the breeding grounds, western Spitsbergen. Nor. Polarinst. Skr. 181, 87-117.

Prop, J. \& Vulink, T. 1992: Digestion by Barnacle geese in the annual cycle: the interplay between retention time and food quality. Funct. Ecol. 6, 180-189.

Raveling, D. J. 1979: The annual cycle of body composition of Canada Geese with special reference to control of reproduction. $A u k$ 96, 234-252.

Sedinger, J. S. \& Raveling, D. G. 1984: Dietary selectivity in relation to availability and quality of food for gosling of Cackling Geese. Auk 101, 295-306.

Sedinger, J. S. \& Raveling, D. G. 1986: Timing of nesting by Canada Geese in relation to the phenology and availability of their food plants. J. Anim. Ecol. 55, 1083-1102.

Sedinger, J. S. \& Raveling, D. G. 1988: Foraging behavior of Cackling Canada Goose goslings: implications of the role of food availability and processing rate. Oecologia 75, 119124.
Sedinger, J. S., White, R. G., Mann, F. E., Burris, F. A. \& Kedrowski, R. A. 1989: Apparent metabolizability of alfalfa components by yearling Pacific Black Brant. J. Wildl. Manage. 53, 726-734.

Spaans, B., Stock, M., St. Joseph, A., Bergmann, H. H. \& Ebbinge, B. S. 1993: Breeding biology of Dark-bellied Brent Geese Branta b. bernicla in Taimyr in 1990 in the absent of Arctic foxes and under favorable weather conditions. Polar Res. 12, 117-130.

Staaland, H., Brattbakk, I., Ekern, K. \& Kildemo, K. 1983: Chemical composition of reindeer forage plants in Svalbard and Norway. Holarct. Ecol. 6, 109-122.

Thompson, S. C. \& Raveling, D. R. 1987: Incubation behaviour of Emperor Geese compared with other geese: interactions of predation, body size and energetics. Auk 104, 707-716.

Tombre, I. M. \& Erikstad, K. E. 1996: An experimental study of incubation effort in High-Arctic Barnacle geese. J. Anim. Ecol. 65, 325-331.

Trudell, J. \& White, R. G. 1981: The effect of forage structure and availability on food intake, biting rate, bite size and daily eating time in reindeer. J. Appl. Ecol. 18, 63-81. 